\title{
PARA FICAR EM CASA É PRECISO TER CASA: A COVID-19 E O DIREITO À MORADIA NO BRASIL ${ }^{1}$
}

\author{
Nino Rafael Medeiros Krüger ${ }^{2}$ \\ Caroline Krüger ${ }^{3}$ \\ Gustavo Henrique Soares Ferreira ${ }^{4}$
}

\section{INTRODUÇÃ $0^{5}$}

O "novo coronavírus, denominado Sars-CoV-2, causador da doença Covid-19", que acarreta infecçôes respiratórias com alta capacidade de contágio e efeitos letais (Lana et al., 2020, p. 1), ainda não possui cura ou sequer um tratamento eficaz no impedimento de sua contaminação. Com rápida disseminação em escala global, ${ }^{6} \mathrm{o}$ vírus colocou em xeque as estratégias historicamente adotadas para o trato com as diversas dimensóes da questáo social - compreendida enquanto desdobramento do conflito entre capital e trabalho nas sociedades capitalistas (Iamamoto, 2001), em especial com a questão da habitação.

Isso porque, devido ao fato de a capacidade dos sistemas de saúde em lidar com a taxa de contaminação pelo vírus no curto prazo ser limitada e os recursos, finitos (leitos hospitalares, número de profissionais de saúde, entre outros), o número de pacientes tratados tornou-se menor que a demanda necessária (Silva, 2020, p. 579). Essa realidade deixou muitos pacientes infectados com condiçóes pulmonares deterioradas sem nenhum tratamento, resultando na necessidade de políticas drásticas de distanciamento físico (Gourinchas, 2020).

Em outras palavras, a recomendação "fique em casa", que partiu de lideranças internacionais, entre as quais se destaca a OMS, tornou-se slogan da campanha contra a disseminação da Covid-19. Contudo, como ficar em casa quando náo se tem moradia, ou ainda quando suas condiçóes são precárias?

1. DOI: http://dx.doi.org/10.38116/brua24art9.

2. Pesquisador doutorando em políticas sociais e direitos humanos na Universidade Católica de Pelotas (UCPel).

3. Pesquisadora doutora lotada na pesquisa Fronteiras do Brasil: uma Avaliação de Política Pública, desenvolvida pela Diretoria de Estudos e Políticas Regionais, Urbanas e Ambientais (Dirur) no Ipea.

4. Pesquisador doutorando lotado na pesquisa Fronteiras do Brasil: uma Avaliação de Política Pública, desenvolvida pela Dirur/lpea. 5. Os autores agradecem a leitura atenta, os comentários e as sugestões do parecerista anônimo que possibilitaram ajustes fundamentais à estrutura e ao conteúdo do texto.

6. 0 vírus foi detectado em 31 de dezembro de 2019 em Wuhan, na China, e em 16 de janeiro em território japonês. Em 30 de janeiro, foi declarado pela Organização Mundial da Saúde (OMS) como emergência internacional (Public Health Emergency of International Concern - Pheic), quando diversos países já haviam confirmado importações de caso, incluindo Estados Unidos, Canadá e Austrália. No Brasil, em 7 de fevereiro, havia nove casos em investigação (Lana et al., 2020). 
No Brasil, a moradia é um direito e um bem fundamental ao desenvolvimento seguro e saudável da vida humana, segundo a Constituição Federal de 1988 (CF/1988) (Brasil, 1988). Porém, aqueles que a acessam de forma precária, ou seja, os habitantes de áreas irregulares, que se caracterizam entre $50 \%$ e $60 \%$ da população brasileira (Ribeiro, 2019; Cunha, 2019), acabam se tornando os alvos principais do contágio e da transmissão da Covid-19 (Srougi, 2020). Esse cenário impinge a necessidade de campanhas que não só impulsionem o isolamento social mas o subsidiem, garantindo-o enquanto direito.

Com esse escopo, este ensaio discute a disseminação da Covid-19 a partir da reflexão sobre o direito à moradia no Brasil. Para isso, além desta breve introdução, são recuperadas questôes históricas e se apresenta uma análise sobre o tema utilizando-se dados do censo demográfico de 2010 (IBGE, 2011), dados preliminares do censo de 2019 (IBGE, 2019), além de dados da Fundação Oswaldo Cruz (Fiocruz) sobre a Covid-19 de 31 de julho de 2020 (Fiocruz, 2020). Finaliza-se o texto nas consideraçóes finais, com apontamentos para a efetivação de políticas públicas sobre o tema.

\section{DIREITO À MORADIA NO BRASIL E A COVID-19}

Internacionalmente, a questão da moradia se tornou objeto de intensas reflexôes e calorosos debates que a lançaram ao âmbito dos direitos fundamentais há mais de meio século. Todavia, mesmo diante de inúmeras conferências, tratados e acordos que abordam o tema e têm a nação brasileira enquanto signatária, esse direito, e o complexo arcabouço dos temas que o envolvem (segurança, infraestrutura, economicidade, habitabilidade, acessibilidade, adequação cultural, localizaçáo etc.), continua a ser ofertado apenas a uma parcela da população, sendo oferecido enquanto bem de consumo (Maricato, 2013), negando sua essência enquanto direito fundamental (Kruger, 2018).

Esse é o cenário que se apresenta e molda a arena sobre a qual se dissemina a Covid-19 no Brasil. Desvela que o modelo de desenvolvimento social que vem há séculos preconizando o econômico, em detrimento do social e ambiental, não suporta mais a vida (Araújo, Mallart e Gaudenzi, 2020). Na natureza mercantilizada no espaço urbano financeirizado, coisificou-se a vida, que agora se expressa enquanto números que rapidamente se perdem, pois a histórica negação do acesso a direitos fundamentais para parte substantiva da população, cedo ou tarde, recai sobre o todo o social.

Diante da pandemia, o apelo "fique em casa" busca chamar a atenção da população mundial para a necessidade da prática do isolamento físico enquanto estratégia voltada ao impedimento da proliferação rápida da Covid-19, que incorreria em colapso dos sistemas de saúde. Contudo, quando ecoado sobre a nação brasileira, acaba se tornando declaração de denúncia da violência da qual essas populaçôes vulneráveis têm sido vítimas por séculos, uma vez que, anteriormente, não tiveram tal direito garantido e agora lhes é cobrado um preço diante do avanço da contaminação.

No lastro colocado por Penalva e Duarte (2010), assevera-se aqui que, diante do tamanho do problema enfrentado, lançar reflexáo sobre a origem dessa crise referente à moradia no país se torna uma questão necessária. Isso porque se observam processos de violência e expulsôes desde a chegada dos invasores portugueses no século XV, quando se iniciam as exploraçôes de recursos naturais tornados em bens de consumo para a impulsão de economias de outras latitudes. Visando à redução do marco temporal, recuperam-se processos desencadeados pela chegada da coroa portuguesa em 1808. A coroa, ao vir acompanhada de uma corte de aproximadamente 15 mil pessoas para as quais não fora preparada previamente a alocaçáo, 
deu início a um processo de desapropriação e expulsão que vitimou substantiva parcela da população, como afirmavam Penalva e Duarte (2010, p. 3), ao retratar que

o problema de acomodar tamanho contingente populacional foi resolvido com a "requisiçáa", pela coroa, das melhores residências da sede da então colônia. A marca "P. R." era a identificação de que a residência tinha sido requisitada. Essa era a marca de "príncipe regente", mas a população logo passou a se referir a ela como "ponha-se na rua", o que, convenhamos, correspondia mais aos fatos.

É um processo violento, que marca a gênese de um problema que se agrava no decorrer dos anos, pela materialização de um modelo de desenvolvimento urbano que não foi pensado para respeitar as características socioculturais locais (Kruger et al., 2020). A sançáo da Lei $\mathrm{n}^{\circ}$ 601/1850, a Lei de Terras (Brasil, 1850), colocou-se enquanto elemento fundamental para o aprofundamento desse processo.

A institucionalização da negaçáo do acesso a terra, bem fundamental para o desenvolvimento e a manutenção da vida, alicerçou a estrutura necessária para o subjugamento e a expulsão daqueles que não têm ao seu alcance recursos suficientes para resistir às açôes dos grupos economicamente dominantes (Holz e Monteiro, 2008). Um segundo processo (Silva, 1996), responsável pela configuração de um desenho de ocupação do solo, se deu de forma desigual e antidemocrática, e para ele instituíram-se instrumentos maniqueístas, os quais acabaram por transformar o Estado em vetor de captura para a potencialização da segregação e do arbítrio.

A proteção da propriedade privada em detrimento da vida deu sustentação a um modelo de exploração voltado ao aprofundamento da acumulaçáo de capitais. Políticas pautadas por valores de mercado operam desde entáo, subordinando trabalhadores a partir da disseminação de racionalidades apresentadas como sendo a única forma possível para o alcance da tão sonhada ordem e progresso (Morais, 2002). Uma razáo que traduz a ideologia ilusória de "bem-estar" coletivo, possibilitando que o Estado se torne uma instância de socorro para o mercado.

As normas jurídicas nesse cenário passam a estabelecer conjuntos de regras para a adaptaçáo das estratégias dessa regulaçáo, e o direito à moradia, discutido em congressos e conferências, publicado em relatórios, é transformado em norma de adequação (PDHJ, 2009; Brasil, 2013) que materializa o controle da sociedade para a manutençáo do modo de produção. Sua concretização constitui uma arena de tensôes sobre a qual se desenham os conflitos que mantêm em expansão o sistema posto (Kruger, 2020).

Assim, são historicamente definidas e planificadas as políticas habitacionais no Brasil. Tal situaçáo recupera as estratégias do Estado no século XIX, que se voltava à garantia dos interesses das elites ruralistas, até o alargamento dos objetivos do mercado da construçáo civil a partir da década de 1960, quando a ideologia da casa própria se torna meta do regime militar, o qual sequestra recursos dos trabalhadores por meio dos fundos de garantia para transferência direta às elites que dominam o mercado construtor (Silva, 1989), definindo o desenho urbano atual. Nesse desenho, quanto menores forem os recursos financeiros da população, mais latente fica a situaçáo de vulnerabilidade, colocando tais grupos em áreas cada vez mais distantes dos centros urbanos, estabelecendo-se marcadores de acesso a infraestrutura, equipamentos, bens e serviços que configuram a violação ao direito à moradia e à cidade (Kruger, 2020).

Uma janela para a reconfiguração dessa estrutura foi vislumbrada com a promulgação do Estatuto da Cidade (Brasil, 2001), com a criação do Ministério das Cidades e dos conselhos com participação popular (Brasil, 2003). Entretanto, o desenvolvimento do 
programa Minha Casa Minha Vida (Brasil, 2009) desconectado das discussóes do Plano Nacional de Habitação (PlanHab), que vinha sendo construído desde 2004, reforçou os processos anteriores, em que recursos expropriados de fundos públicos foram utilizados para salvar o mercado (Nabuco, Primi e Nabuco, 2014). Valores que deveriam ser destinados ao desenvolvimento de políticas sociais como seguridade social, políticas de assistência, saúde e educação passaram a ser transferidos para os construtores (Rodrigues e Salvador, 2011).

Desse modo, impóe-se a necessidade do desenvolvimento de reflexáo crítica sobre as estratégias adotadas para o trato com as diversas dimensóes da questão social - contexto no qual se insere a questáo habitacional, negada enquanto direito e bem fundamental ao desenvolvimento seguro e saudável da vida. Aqueles que não têm acesso à moradia ou que a acessam de forma irregular ou precária se tornaram alvos potenciais do vírus.

Cabe destacar que, no período de governo do ex-presidente Michael Temer, se reafirmou o compromisso do Estado com o setor privado da construção, e se aprofundaram processos de negação de direitos aos grupos historicamente desprotegidos (Kruger, 2020). Esses fatos foram materializados na diminuição dos recursos para a linha do Minha Casa Minha Vida direcionada aos grupos de baixa renda, na criação de uma nova modalidade do programa voltada ao mercado (Souza e Hoff, 2019) e na promulgaçáo da Emenda Constitucional no 5 também conhecida como Emenda Constitucional do Teto dos Gastos Públicos, alterou a CF/1988 ao instituir o Novo Regime Fiscal, congelando por vinte anos os investimentos que deveriam ocorrer em habitação, saúde, educação (Brasil, 2016).

Uma situação ainda mais complexa se deu no atual governo, em que os espaços institucionais de participação popular foram eliminados, extinguiu-se o Ministério das Cidades - uma conquista histórica dos movimentos populares que lutam pela reforma urbana - e funcionários de carreira desse ministério foram alocados em cargos subalternos (Brasil, 2019). Além disso, ele foi fundido com o Ministério da Integração, resultando no Ministério do Desenvolvimento Regional (MDR). Foram cancelados também os recursos para os projetos de habitação de interesse social (grupos de baixa renda) e aprofundou-se a precarização nas condiçôes de moradia, que agora vem à tona de forma indelével (Kruger, 2020).

Nesse cenário, a convocação "fique em casa”, ao se deparar com uma nação estruturada sobre o trato da moradia enquanto objeto de mercado, artigo colocado à disposiçáo somente daqueles que têm como arcar financeiramente com seus custos, acaba expondo a tática de controle socioterritorial da população, por meio dos marcadores de diferenciação social (Pina, 2018). O acesso à moradia pelo mercado acaba funcionado enquanto fronteira que delimita os espaços de promoçáo da infraestrutura urbana, selecionando aqueles que serão alvo da proteção social dos demais. Isso é parte de um processo que manifesta a tragédia que as cidades se tornaram (Rolnik, 2015), onde a moradia para substantiva camada da população não pode ser considerada refúgio ou espaço de garantia de segurança contra a pandemia (Alfonsin, 2020).

Assim, à medida que o vírus se propaga no país e alcança as cidades com baixos índices de infraestrutura urbana, como nos casos registrados nos estados do Norte (mapas 1A e 1B), bem como nas comunidades periféricas (Bombardi e Nepomuceno, 2020), ele vai alterando o que se tem considerado internacionalmente enquanto grupos de risco. ${ }^{7}$ Isso ocorre porque, primeiramente, a letalidade do vírus estava "majoritariamente associada a pacientes idosos ou à presença de comorbidades que afetam o sistema imunológico" (Lana et al., 2020, p. 2),

7. Disponível em: <https://bit.ly/3g2pgnH>. 
passando a vitimar as periferias das cidades, onde habita grande parte da população excluída no processo de urbanizaçáo (Srougi, 2020).

À vista disso, verifica-se que a coabitação, o ônus excessivo de aluguel, os altos índices de adensamento populacional em áreas onde falta infraestrutura urbana básica (mapas 1C e 1D), os aglomerados sem acesso a saneamento, calçamento, água, como também apontam os dados dos aglomerados subnormais do censo do Instituto Brasileiro de Geografia e Estatística (IBGE), imprimem o marcador de risco nos corpos que esses territórios habitam.

\section{MAPA 1}

\section{Infraestrutura urbana}

1 A - Percentual de domicílios com abastecimento de água e esgotamento sanitário inadequados

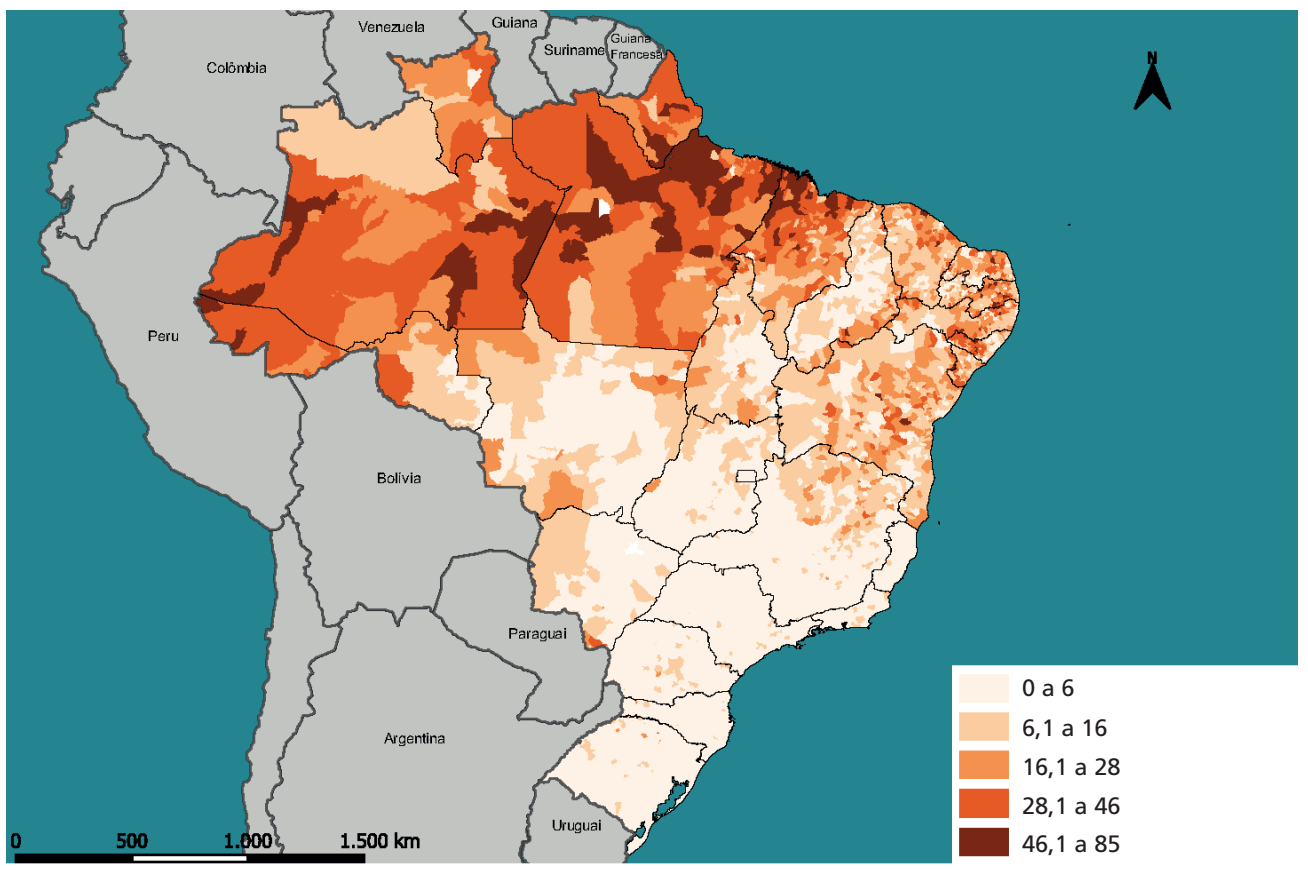

1B - Percentual de domicílios sem o serviço de coleta de lixo

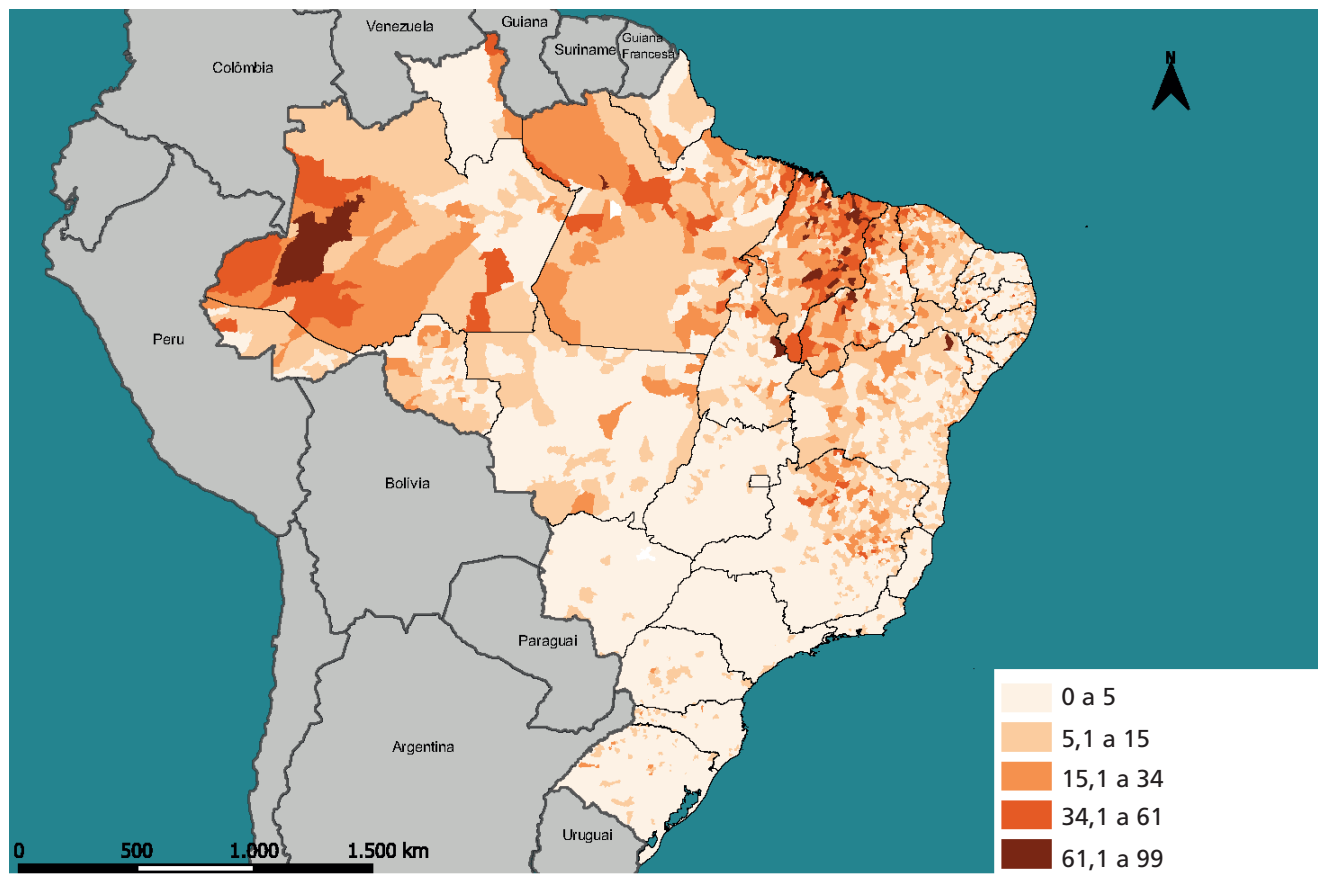


1C - Média de moradores por domicílio

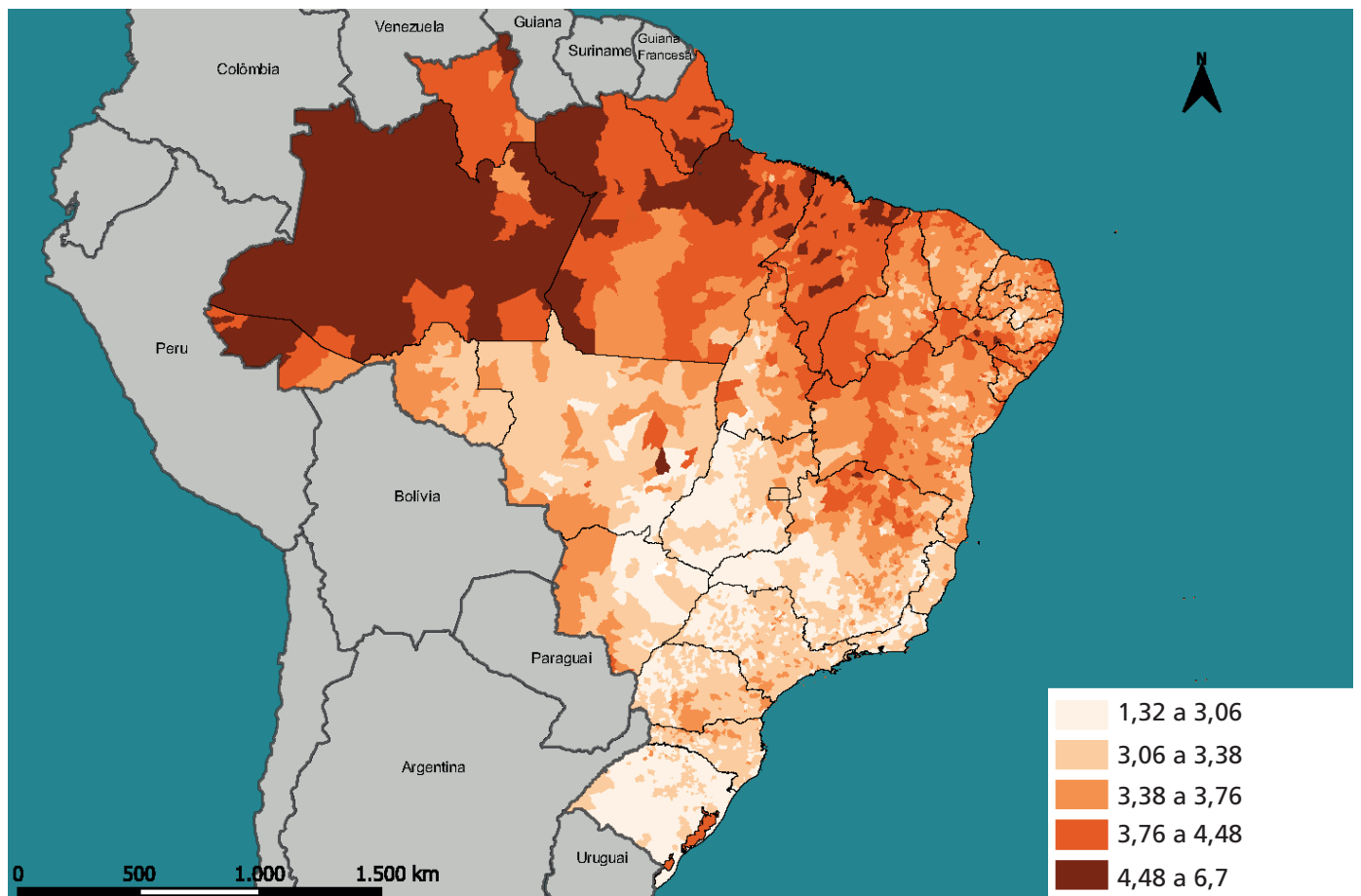

1D - Média de moradores por dormitório

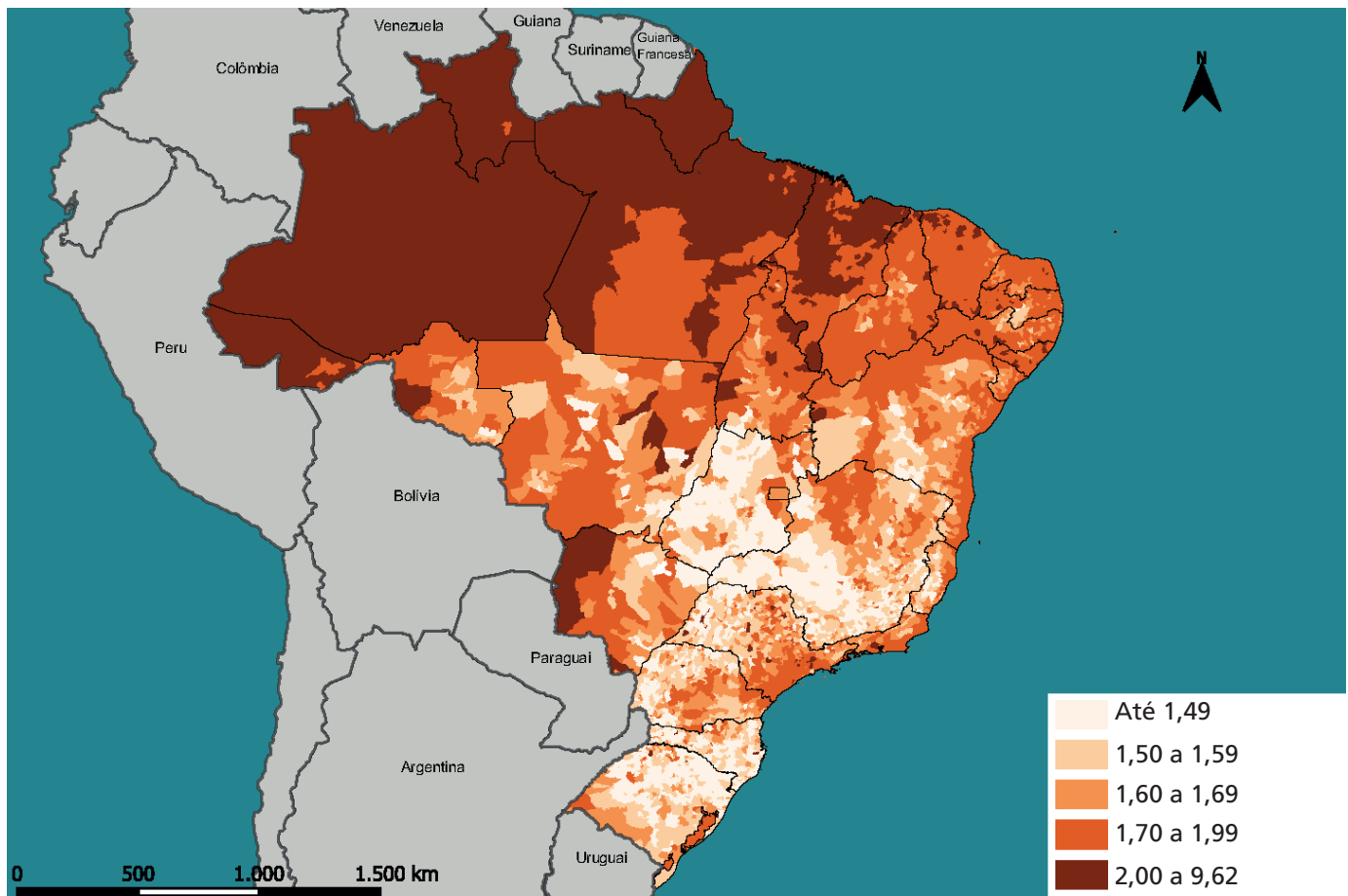

Fonte: IBGE (2011)

Elaborado pelos autores.

Nesse ínterim, outro dado relevante se refere ao impacto da Covid-19 nas periferias brasileiras, pois, ao analisar esses resultados, percebe-se que os óbitos nos espaços sem infraestrutura urbana chegam a ser oito vezes maiores que nos bairros providos desse serviço (Carvalho, 2020) (mapas 2A e 2B). Além disso, os marcadores de escolaridade e raça, que delimitam uma condição socioeconômica estrutural na sociedade, são potencializadores dos riscos (Agência Pública, 2020; Costa, 2020). Complementarmente, segundo a organização 
não governamental (ONG) Rede Nossa São Paulo, no Brasil, o fator de risco para que a Covid-19 seja letal é o endereço, estando a falta de infraestrutura básica para habitação e higiene relacionada diretamente com as taxas de mortalidade do vírus.

MAPA 2

Covid-19: incidência de casos, óbitos e estabelecimentos de saúde 2A - Incidência de casos por 1 milhão de habitantes (31 jul./2020)

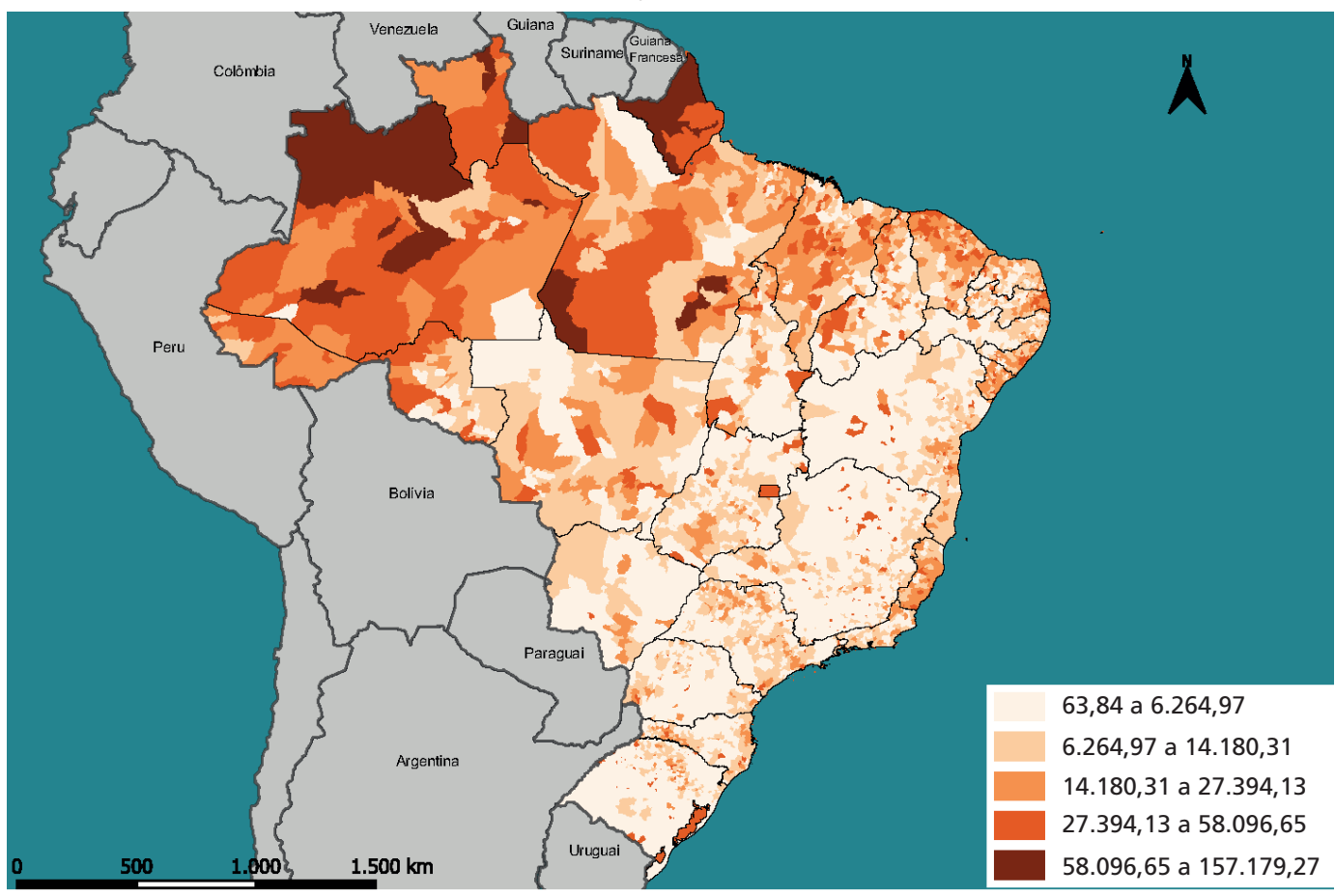

2B - Incidência de óbitos por 1 milhão de habitantes (31 jul./2020)

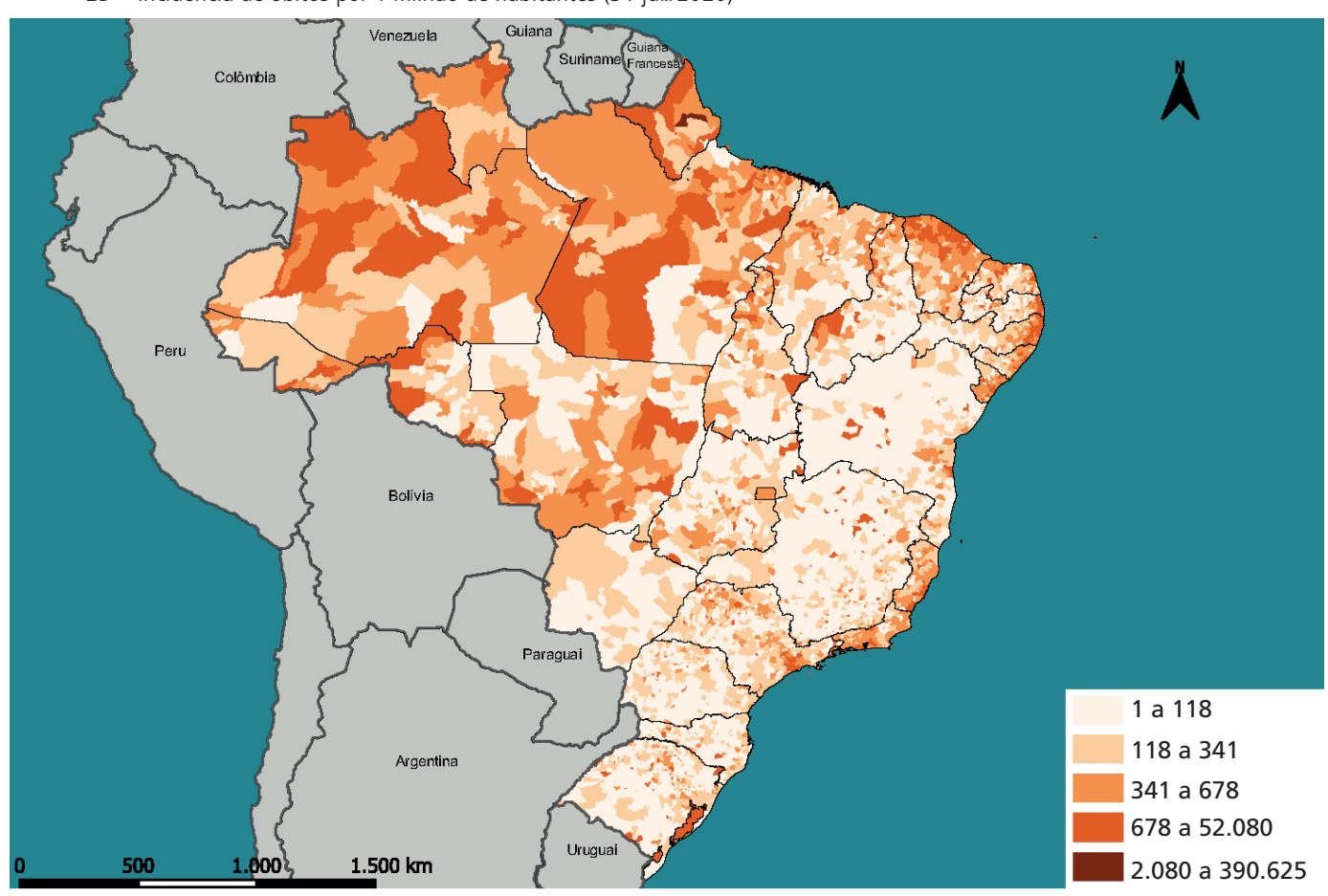


2C - Estabelecimentos de saúde de atenção primária

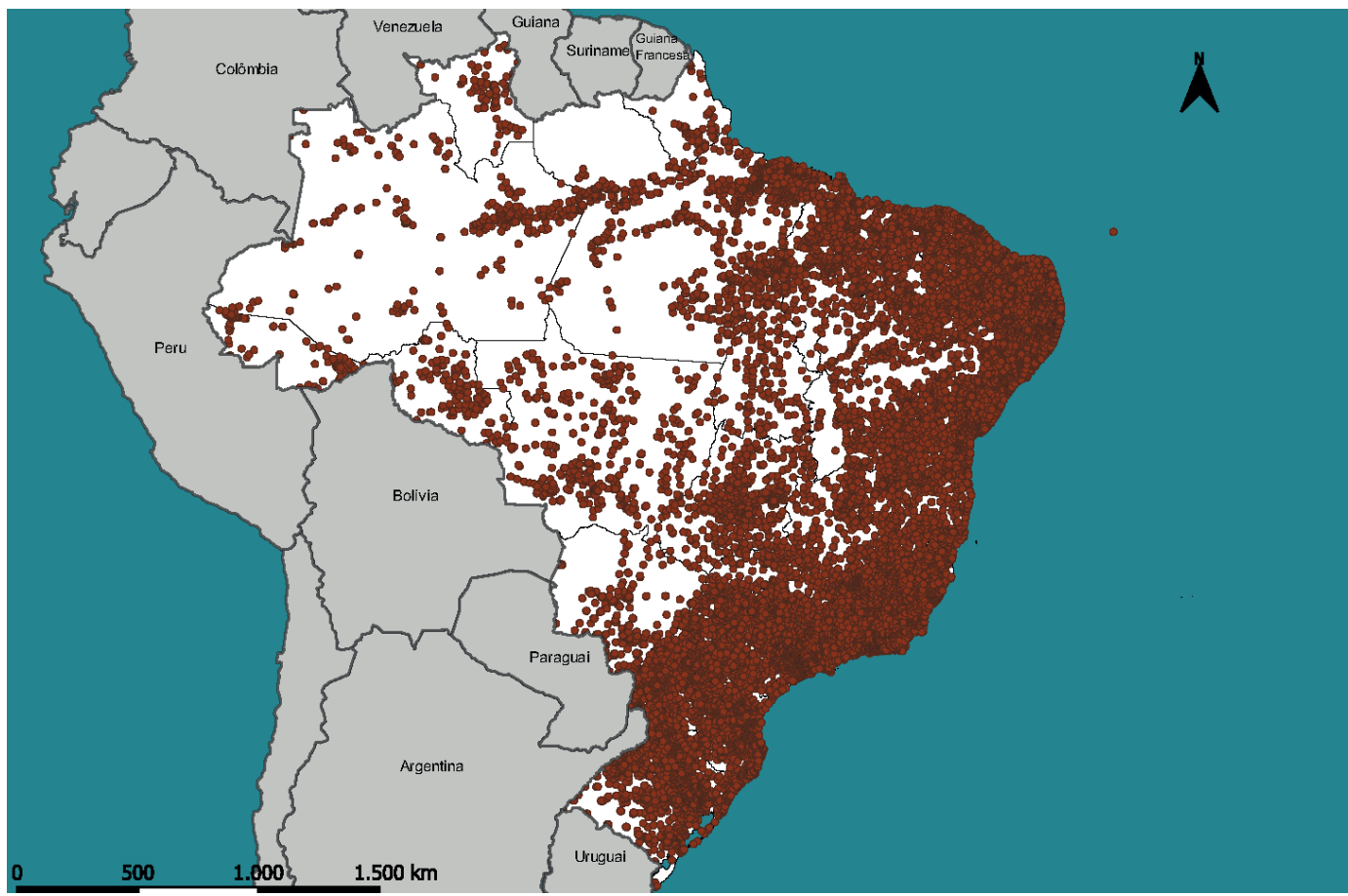

2D - Estabelecimentos de saúde com suporte de observação e internação

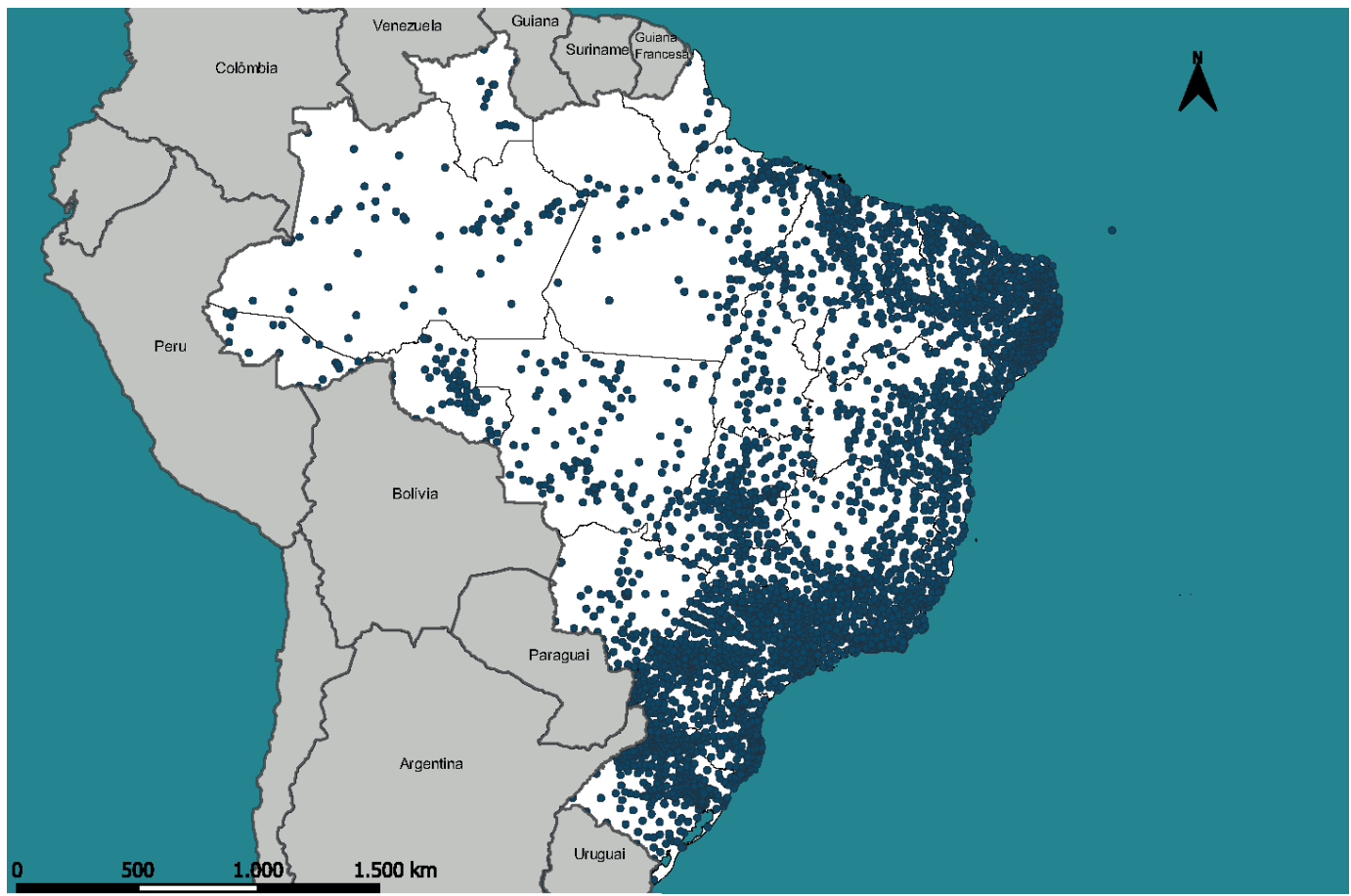

Fonte: Fiocruz (2020)

Elaborado pelos autores.

Importante ainda ressaltar que o encontro de uma crise econômica com uma "outra política" resultou no desmonte das políticas urbanas para o país (Vainer, 2013), que, ao se confrontarem com a pandemia, tornaram explícita a desigualdade socioterritorial urbana brasileira, reverberando na premência de medidas para o fortalecimento do sistema de proteção social. Esse sistema, por sua vez, vem sofrendo, ao longo dos últimos anos, pesadas 
reduções orçamentárias, como no caso já citado do congelamento de gastos primários por meio da Emenda Constitucional no 95 (Brasil, 2016).

Em decorrência da redução orçamentária, um preço muito alto frente à proliferação do vírus tem sido pago, uma vez que grande parcela das cidades brasileiras possui deficit de estabelecimentos de atenção básica de saúde e de estabelecimentos de saúde com suporte de observação e internação (mapas 2C e 2D), tornando precária a capacidade de atendimento e o suporte no cenário pandêmico.

Ainda que nos atestados de óbito das vítimas dessa crise civilizacional encontre-se marcado "morte por coronavírus", na maioria dos casos, o que as terá matado é a negligência - o Estado, muitas vezes, em detrimento da proteção de seus cidadáos, volta-se para o mercado, concedendo a ele todos os benefícios possíveis por meio da subtração de recursos/direitos dos grupos vulneráveis. A análise dos relatórios do Plano de Aceleração do Crescimento (PAC) que tratam do programa Minha Casa Minha Vida (Brasil, 2014; 2018) apresenta um panorama de tal inversão de prioridades no ato da planificação de políticas públicas. Esses relatórios demonstram que, mesmo se reconhecendo que o deficit habitacional no país se encontra substancialmente entre os grupos com renda inferior a três salários mínimos - 89\%, faixa de renda tida como prioridade do programa (Brasil, 2009) -, os investimentos para a produção de moradias para os grupos encontrados acima dos três salários mínimos foram de mais de 60\% do orçamento (Chiarelli, 2014; Brasil, 2018).

Um tema em discussão que poderia corroborar a melhoria deste cenário é a reforma tributária no Brasil. Segundo o último Relatório de Desenvolvimento Humano da Organização das Naçôes Unidas (ONU), ${ }^{8}$ no Brasil, o $1 \%$ mais rico concentra quase um terço da renda de quase $30 \%$ da população, o que dá ao país o título de vice-campeão mundial em desigualdade, só perdendo por $0,7 \%$ para o Catar. Além disso, cinco bilionários brasileiros concentram a mesma riqueza que a metade mais pobre do país, segundo estudo da Oxfam Brasil,, ou seja, cinco pessoas concentram o mesmo patrimônio que 100 milhóes de brasileiros.

Essa é a situação que a Covid-19 desnuda, ao apresentar-se enquanto um vírus trazido ao país por pessoas economicamente privilegiadas, e tornar mais vulneráveis a seus riscos aqueles que, sem alternativa, têm de se entregar ao serviço desses. As principais vítimas da pandemia permanecem sendo as históricas vítimas dessa estrutura.

\section{CONSIDERAÇÕES FINAIS: DIRECIONAMENTOS PARA POLÍTICAS PÚBLICAS}

No momento em que as autoridades sanitárias internacionais apontam para a necessidade do isolamento físico como estratégia para o impedimento da proliferação do vírus, e destacam a importância de hábitos de higiene, grupos que não têm direito a saneamento e moradia são mantidos em áreas com precária infraestrutura urbana, sendo impedidos de se proteger adequadamente. Sáo milhares os assentamentos irregulares em que esses grupos sofrem por conta do adensamento populacional, espaços que não possuem abastecimento de água potável regular.

Essa situação torna urgente a reflexão sobre a realidade na qual a violação de direitos positivados, como a "garantia do direito a cidades sustentáveis, entendido como o direito à terra urbana, à moradia, ao saneamento ambiental, à infraestrutura urbana, ao transporte e aos serviços públicos, ao trabalho e ao lazer, para as presentes e futuras geraçóes" (Brasil,

8. Disponivel em: <https://bit.ly/3fhZZ8s >.

9. Disponível em: <https://bit.ly/3yxR5eR>. 
2001), deixa mais de $60 \%$ da população sem acesso a tratamento de esgoto (Ipea, 2016). Esse cenário estabelece um panorama potente para a ampliação da contaminação pela Covid-19.

Verifica-se que a busca pela garantia do direito a uma moradia digna se entrelaça à conquista do direito à cidade - um direito coletivo que engloba variados aspectos dos direitos urbanos -, compreendido pelo relatório do Ipea para o Habitat III como um novo paradigma para repensar os processos de urbanização e as cidades brasileiras, voltado ao cumprimento de todos os direitos humanos que outrora foram acordados internacionalmente (Ipea, 2016). Assim, a garantia desse direito, conforme exposto na legislação brasileira, deveria transformar a situação dos grupos atualmente mantidos sem acesso à moradia, processo que é resultado de décadas de violação/omissão por parte dos governantes em todas as esferas e entes da Federação.

Para que o isolamento físico, uma das principais recomendaçôes das autoridades sanitárias para o enfrentamento da pandemia, possa ocorrer adequadamente para a população em situação de vulnerabilidade, é primordial que os instrumentos que garantem a função social da propriedade constantes dentro da legislação sejam colocados em ação. Dessa maneira, os governos municipais passariam a utilizar, durante o período pandêmico, para tais grupos, a requisição administrativa de imóveis abandonados, não utilizados pelo poder público municipal, e até mesmo quartos de hotel. Esse instrumento se fundamenta no art. 5, inciso XXV, da $\mathrm{CF} / 1988$, que descreve que, "no caso de iminente perigo público, a autoridade competente poderá usar de propriedade particular, assegurada ao proprietário indenização ulterior, se houver dano" (Brasil, 1988).

Para tanto, entende-se necessário um maior comprometimento por parte do poder público na esfera municipal, que deve adotar uma postura proativa diante da realidade vivenciada no país, reconhecendo as ocupaçóes em áreas públicas e terrenos que não cumprem função social enquanto estratégias para a garantia da proteção contra o vírus, que se constitui, neste contexto, um direito. Ademais, entende-se que podem ser desenvolvidos programas de incentivo à doação de materiais de construção e à elaboração de bancos de matérias, para a disponibilização a famílias que sofrem com o problema da coabitação, além de bancos de terras, a partir do mapeamento de terras públicas e privadas que não cumprem função social e podem ser alvo de desapropriação - conforme o inciso XXIV do art. 5o da CF/1988 (Brasil, 1988).

A cobrança de Imposto sobre a Propriedade Predial e Territorial Urbana (IPTU) de forma progressiva, constante, na mesma legislação e que se volta ao desestímulo da manutenção de propriedades improdutivas poderia servir para a criação de recursos para o desenvolvimento de programas de aluguel social para famílias desprotegidas. Para os casos de remoçôes ou reintegraçóes de posse, aponta-se a necessidade de serem criadas câmaras de conciliaçáo, previstas no art. 34 da Lei no 13.465 (Brasil, 2017), para a mediação dos processos e a garantia dos direitos das populaçôes. Do mesmo modo, precisa-se da suspensão das reintegraçôes de posse e despejo no período da pandemia, bem como da criação de protocolos de remoção, para a garantia de direitos das populaçóes vitimadas por tais processos fora do período pandêmico. Sobre os despejos, cabe destacar ainda a necessária implementação da proposta de quarenta entidades do Brasil e do exterior, que se uniram e lançaram a campanha Despejo Zero em julho de 2020 (Lacerda, 2020). Essa ação está voltada à suspensão de atividades que violem direitos, sejam fruto de açóes despendidas por entes privados ou públicos, que tenham respaldo em decisóes judiciais ou administrativas e que objetivem desabrigar famílias e comunidades no período da pandemia. 


\section{REFERÊNCIAS}

AGÊNCIA PÚBLICA. Em duas semanas, número de negros mortos por coronavírus é cinco vezes maior no Brasil. Carta Capital, 7 maio 2020. Disponível em: <https://bit.ly/2QPezLm>. Acesso em: 8 maio 2020.

ALFONSIN, B. de M. A tutela do direito à cidade em tempos de Covid-19. Observatório das Metrópoles, 2020. Disponível em: <https://bit.ly/3hUz9VF>. Acesso em: 21 ago. 2020.

ARAÚJO, F.; MALLART, F.; GAUDENZI, P. Contextualizar o desmonte é essencial. Labcidade, jul. 2020. Disponível em: <https://bit.ly/3vohtpy>. Acesso em: 21 ago. 2020.

BOMBARDI, M. L.; NEPOMUCENO, P. L. M. Covid-19, desigualdade social e tragédia no Brasil. Le Mond Diplomatique Brasil, 29 abr. 2020. Disponível em: <https://bit.ly/3w3csTl>. Acesso em: 7 jun. 2021.

BRASIL. Lei no 601, de 18 de setembro de 1850. Dispóe sobre as terras devolutas do Império. Collecção das Leis do Imperio do Brazil, 1850. Disponível em: <https://bit.ly/2SIS2pY>. Acesso em: 24 abr. 2018.

Constituição da República Federativa do Brasil de 1988. Brasília: Senado Federal, 1988. Disponível em: <https://bit.ly/3viS6W0>. Acesso em: 12 ago. 2020.

. Lei no 10.257 , de 10 de julho de 2001. Regulamenta os arts. 182 e 183 da Constituição Federal, estabelece diretrizes gerais da política urbana e dá outras providências. Diário Oficial da Uniâo, Brasília, 11 jul. 2001. Disponível em: <https://bit.ly/2RHzv7q>. Acesso em: 9 out. 2017.

. Lei no 10.683 , de 28 de maio de 2003. Dispóe sobre a organização da Presidência da República e dos ministérios, e dá outras providências. Diário Oficial da União, Brasília, 29 maio 2003. Disponível em: <https://bit.ly/3ujkKoH>. Acesso em: 6 jun. 2018.

. Lei no 11.977 , de 7 de julho de 2009. Dispóe sobre o Programa Minha Casa Minha Vida - PMCMV e a regularizaçấo fundiária de assentamentos localizados em áreas urbanas; altera o Decreto-Lei no 3.365, de 21 de junho de 1941, as leis nos 4.380, de 21 de agosto de 1964, 6.015, de 31 de dezembro de 1973, 8.036, de 11 de maio de 1990, e 10.257, de 10 de julho de 2001, e a Medida Provisória no 2.197-43, de 24 de agosto de 2001; e dá outras providências. Diário Oficial da União, Brasília, 8 jul. 2009. Disponível em: <https://bit.ly/2RA9N4T>. Acesso em: 9 out. 2017.

- Secretaria de Direitos Humanos da Presidência da República. Direito à moradia adequada. Brasília: Coordenação Geral de Educação em SDH/PR, Direitos Humanos, Secretaria Nacional de Promoção e Defesa dos Direitos Humanos, 2013. Disponível em: <https://bit. ly/3hOzVU2>. Acesso em: 29 set. 2017.

PAC2: a gente faz um Brasil de oportunidades - balanço 4 anos (2011 a 2014). [s.l.]: [s.n.], 2014. Disponível em: <https://bit.ly/3wvfP5A>. Acesso em: 15 jun. 2018.

. Emenda Constitucional no 95, de 15 de dezembro de 2016. Altera o Ato das Disposiçóes Constitucionais Transitórias, para instituir o Novo Regime Fiscal, e dá outras providências. Diário Oficial da União, Brasília, 15 dez. 2016. Disponível em: <https://bit.ly/3fioAdy>. Acesso em: 21 ago. 2020. 
. Lei no 13.465 , de 11 de julho de 2017. Dispõe sobre a regularização fundiária rural e urbana, sobre a liquidação de créditos concedidos aos assentados da reforma agrária e sobre a regularização fundiária no âmbito da Amazônia Legal; institui mecanismos para aprimorar a eficiência dos procedimentos de alienação de imóveis da União. Diário Oficial da Uniáo, Brasília, 12 jul. 2017. Disponível em: <https://bit.ly/3fdRThg>. Acesso em: 21 ago. 2020.

PAC: 6o balanço - 2015-2018. Brasília: SDI, 2018. Disponível em: <https://bit. ly/3wJ7H1x>. Acesso em: 15 jun. 2018.

. Lei no 13.844 , de 18 de junho de 2019. Estabelece a organização básica dos órgãos da Presidência da República e dos ministérios. Diário Oficial da Uniáo, Brasília, 18 jun. 2019. Disponível em: <https://bit.ly/3yyDAeJ>. Acesso em: 21/08/2020.

CARVAlHO, P. Covid-19: mortes se concentram nas áreas pobres de São Paulo. Veja Sáo Paulo, 18 abr. 2020. Disponível em: <https://bit.ly/2QRjQ58>. Acesso em: 25 maio 2020.

CHIARELLI, L. M. A. Habitaçáo social em Pelotas (1987-2010): influência das políticas públicas na promoçấo de conjuntos habitacionais. 2014. Tese (Doutorado) - Instituto de Filosofia e Ciências Humanas, Pontifícia Universidade Católica do Rio Grande do Sul, Porto Alegre, 2014.

COSTA, S. A pandemia expôs o apartheid não oficial do Brasil em toda a sua brutalidade entrevista com Eliane Brum. Instituto Humanitas Unisinos, 29 abr. 2020. Disponível em: $<$ https://bit.ly/3yAVm16>. Acesso em: 30 abr. 2020.

CUNHA, M. M. 60\% dos imóveis de brasileiros estão irregulares, aponta ministério. Associaçáo dos Notários e Registradores do Brasil, maio 2019. Disponível em: <https://bit.ly/3ff5rc7>. Acesso em: 21 ago. 2020.

FIOCRUZ - FUNDAÇÃO OSWALDO CRUZ. Monitora Covid-19. Brasília: Fiocruz, 2020. Disponível em: <https://bigdata-covid19.icict.fiocruz.br/>. Acesso em: 10 ago. 2020.

GOURINCHAS, P. O. Flattening the pandemic and recession curves. In: BALDWIN, R.; DIMAURO, B. W. (Eds.). Mitigating the Covid economic crisis: act fast and do whatever it takes. London: CEPR Press, 2020.

HOLZ, S.; MONTEIRO, T. V. de A. Política de habitacáo social e o direito a moradia no Brasil. In: COLOQUIO INTERNACIONAL DE GEOCRÍTICA: DIEZ AÑOS DE CAMBIOS EN EL MUNDO, EN LA GEOGRAFÍA Y EN LAS CIENCIAS SOCIALES, 1999-2008, 5., 2008, Barcelona. Anales... Barcelona: UB, 2008.

IAMAMOTO, M. V. A questão social no capitalismo. Temporalis, n. 3, 2001.

IBGE - INSTITUTO BRASILEIRO DE GEOGRAFIA E ESTATÍSTICA. Censo demográfico 2010. Rio de Janeiro: IBGE, 2011.

. Estimativas da populaçáo residente no Brasil e Unidades da Federaçáo com data de referência em 1ํㅜ de julho de 2019. Rio de Janeiro: IBGE, 2019.

IPEA - INSTITUTO DE PESQUISA ECONÔMICA APLICADA. Relatório brasileiro para a Habitat III. Brasília: ConCidades; Ipea, 2016. Disponível em: <https://bit.ly/34bDEmP>. Acesso em: 26 ago. 2020.

KRUGER, N. R. M. O plano perfeito: da retórica do direito à moradia a planificação do Programa Minha Casa Minha Vida em Pelotas à negação do habitar. 2018. Dissertação (Mestrado) - Universidade Católica de Pelotas, Pelotas, jun. 2018. 
. Fique em casa? A questão habitacional no Brasil, da retórica sobre o direito à moradia e o Programa Minha Casa Minha Vida até a realidade pandêmica. Porto Alegre: Editora Fi, 2020.

KRUGER, N. R. M. et al. Para uma descolonialidade do pensamento sobre a cidade. In: SEMINÁRIO DE POLÍTICAS SOCIAIS NO MERCOSUL, 7., 2020, Pelotas. Anais... Pelotas: UCPel, 2020. p. 553-564.

LACERDA, N. Movimentos lançam campanha Despejo Zero por proteção à moradia durante a pandemia. Brasil de Fato, jul. 2020. Disponível em: <https://bit.ly/3hWd21j>. Acesso em: 21 ago. 2020.

LANA, R. M. et al. Emergência do novo coronavírus (Sars-CoV-2) e o papel de uma vigilância nacional em saúde oportuna e efetiva. Caderno de Saúde Pública, v. 36, n. 3, p. 1-5, 2020.

MARICATO, E. As ideias fora do lugar e o lugar fora das ideias. In: VAINER, C. A cidade do pensamento único: desmanchando consensos. Petrópolis: Vozes, 2013.

MORAIS, J. L. B. de. As crises do Estado e da Constituiçáo e a transformaçáo espacial dos direitos humanos. Porto Alegre: Livraria do Advogado, 2002.

NABUCO, A.; PRIMI, L.; NABUCO, W. Luta por um teto. Revista Caros Amigos, jul. 2014.

OSÓRIO, L. M. Direito à moradia adequada na América Latina. In: ALFONSIN, B. de M.; FERNADES, E. Direito à moradia e segurança da posse no Estatuto da Cidade: diretrizes, instrumentos e processos de gestão. Belo Horizonte: Editora Fórum, 2006.

PDHJ - PROVEDORIA DOS DIREITOS HUMANOS E JUSTIÇA. Compilaçáo de instrumentos internacionais de direitos humanos. 1. ed. [s.1.]: UNDP, 2009. Disponível em: <https://bit.ly/2T8YXmA>. Acesso em: 20 abr. 2018.

PENALVA, A. M. S.; DUARTE, S. M. Política habitacional no Brasil: uma nova abordagem para um velho problema. Revista da Faculdade de Direito da Uerj, n. 18, 2010.

PINA, R. Raquel Rolnik: "A captura da política habitacional pela lógica financeira é perversa". Brasil de Fato, 28 maio 2018. Disponível em: <https://bit.ly/2SsriEg>. Acesso em: 11 jun 2018.

RIBEIRO, L. Metade dos imóveis no país são irregulares, segundo ministério. Correio Braziliense, jul. 2019. Disponível em: <https://bit.ly/3fl8OaB>. Acesso em: 21 ago. 2020.

RODRIGUES, T. A.; SALVADOR, E. As implicaçóes do Programa de Aceleraçáo do Crescimento (PAC) nas políticas sociais. Revista Ser Social, Brasília, v. 13, n. 28, p. 129-156, jan./jun. 2011.

ROLNIK, R. Guerra dos lugares: a colonização da terra e da moradia na era das finanças. São Paulo: Boitempo, 2015.

SILVA, G. A. B. et al. Capacidade do sistema de saúde nos municípios do Rio de Janeiro: infraestrutura para enfrentar a Covid-19. Revista de Administração Pública, v. 54, n. 4, p. 578-594, 2020.

SILVA, L. M. O. Terras devolutas e latifúndio: efeitos da Lei de 1850. Campinas: Editora da Unicamp, 1996.

SILVA, M. O. da S. Política habitacional brasileira: verso e reverso. São Paulo: Cortez, 1989.

SOUZA, M. B. de; HOFF, T. S. R. O governo Temer e a volta do neoliberalismo no Brasil: possíveis consequências na habitação popular. Revista Brasileira de Gestão Urbana, v. 11, 23 set. 2019. Disponível em: <https://bit.ly/34dLPyS>. Acesso em: 21 ago. 2020. 
SROUGI, M. Coronavírus: 'Pobres morrerão nas portas dos hospitais', diz professor da USP. O Globo, 23 mar. 2020. Disponível em: <https://glo.bo/3hSCRil>. Acesso em: 24 ago. 2020.

VAINER, C. A cidade do pensamento único: desmanchando consensos. Petrópolis: Vozes, 2013. 